\title{
Moving Beyond the Gym: Exploring Life Skill Transfer Within a Female Physical Activity-Based Life Skills Program
}

\section{Corliss Bean, Kelsey Kendellen \& Tanya Forneris}

To cite this article: Corliss Bean, Kelsey Kendellen \& Tanya Forneris (2015): Moving Beyond the Gym: Exploring Life Skill Transfer Within a Female Physical Activity-Based Life Skills Program, Journal of Applied Sport Psychology, DOI: 10.1080/10413200.2015.1124155

To link to this article: $h$ ttp://dx.doi.org/10.1080/10413200.2015.1124155

Accepted author version posted online: 08 Dec 2015.

Submit your article to this journal $\sqsubset$

ai

View related articles $\sqsubset$

View Crossmark data $\nearrow$ 
5 Moving Beyond the Gym: Exploring Life Skill Transfer Within a Female Physical Activity-

${ }^{1}$ School of Human Kinetics, University of Ottawa 125 University Private Ottawa, Ontario, Canada

\section{K1N 6N5}

14

Email: cbean@uottawa.ca

Phone: 1 (613) 240-0358 
Abstract

28 Physical activity programs are viable contexts to foster life skills. Researchers contend that

29 programs must be structured to deliberately teach life skills and how such skills can be

30 transferred. The purpose of this study was to understand female youths' perceptions of life skills

31 transfer from participation in a physical activity-based life skills program. Interviews were

32 conducted with eight youth. Results indicated that youth learned intrapersonal (i.e., emotional

33 regulation, focus, goal setting) interpersonal (i.e., respect, responsibility, social skills), and

34 physical activity skills and applied these skills in other life domains. Leaders' practical strategies

35 used to explicitly teach transferable skills are discussed.

36 Keywords: Positive Youth Development, physical activity, qualitative methods, life

37 skills, transfer 
Moving Beyond the Gym: Exploring Life Skill Transfer within a Female Physical Activity-

The Positive Youth Development (PYD) framework was developed in response to the

42 deficit-reduction approach that viewed youth as problems to be managed within society and in

43 turn, focused on minimizing problem behaviors (Damon, 2004). This framework emerged from

44 the field of positive psychology, which focuses on building necessary strengths and qualities that

45 help individuals and communities flourish (Lerner, 2012; Snyder \& Lopez, 2002). Such qualities

46 can be wide-ranging and include psychological attributes, life skills, and health habits.

47 Researchers have recognized that life skills are a critical component for enhancing psychosocial

48 development within sport and physical activity programs (Danish \& Nellen, 1997; Gould \&

49 Carson, 2008; Petitpas, Cornelius, Van Raalte, \& Jones, 2005).

50 Life skills have been defined in many ways (Gould \& Carson, 2008). For the purpose of

51 this study life skills were defined as "skills that enable individuals to succeed in the different

52 environments in which they live, such as school, home, and in their neighborhoods" (Danish et

53 al., 2004, p. 40). According to these authors, life skills can be generally classified as

54 intrapersonal (e.g., focus, perseverance, goal setting, emotional regulation) or interpersonal (e.g.,

55 sportspersonship, honesty, teamwork, respect). Intrapersonal skills refer to skills that are more

56 internal in nature whereas interpersonal skills refer to skills that are more useful during social

57 interactions. It is critical to note that one major component of life skills includes the necessity of

58 skill transfer and application to other contexts outside of where it was learned, such as school,

59 home, work, and/or community (Danish et al., 2004; Gould \& Carson, 2008; Papacharisis,

60 Goudas, Danish, \& Theodorakis, 2005), helping youth develop the capacity to successfully cope 
61 with various life situations (Gould \& Carson, 2008; Papacharisis et al., 2005; Petitpas et al., 62 2005).

63 Some researchers have argued that the transference of life skills is not immediate,

64 encouraging coaches and programmers to take this into consideration when developing and

65 implementing life skills programs (Allen, Rhind, \& Koshy, 2015; Petitpas et al., 2005). For

66 example, within Petitpas et al.'s (2005) framework for planning youth sport programs that foster

67 psychosocial development, the authors assert that for successful transference to occur, coaches

68 and program leaders need to help youth identify transferable skills and provide opportunities for

69 them to practice these skills. Also, within Gould and Carson's (2008) model of coaching life

70 skills in sport, the fifth and final component of the model highlights factors influencing the

71 transferability of life skills to non-sport settings (e.g., perceived value of the skill, confidence in

72 ability to transfer, comprehension of transfer, support or reinforcement transfer).

73 Recently Turnnidge, Côté, and Hancock (2014) wrote a position paper which discussed

74 two ways life skill transfer can be facilitated within a sport context; using an implicit or explicit

75 approach. An implicit approach to transfer directs attention towards developing sport-specific

76 outcomes, but does not deliberately frame these outcomes as transferable skills (e.g., a coach that

77 discusses the application of leadership within a sport context, but does not reference how this

78 skill can be utilized in contexts beyond sport). An explicit approach involves fostering an

79 environment in which the transferability of skills is explicitly taught by coaches (e.g., leadership

80 is not only taught within the sport context, but the coach also makes reference to how this skill

81 can be applied in other contexts outside of sport). Although both approaches have been shown to

82 facilitate life skill transfer within the literature (e.g., Camiré \& Trudel, 2010; Camiré, Trudel, and 
83 Forneris, 2012; Holt, Tink, Mandigo, \& Fox, 2008; Walsh et al., 2010), no studies to our

84 knowledge have examined which approach is more likely to lead to transferable skills.

85 Camiré and colleagues (2012) used both athlete and coach perspectives to explore

86 philosophies and strategies used by model coaches to teach and transfer life skills. Findings

87 indicated that many coaches used deliberate strategies to educate their athletes on how to develop

88 and transfer life skills to other domains, such as the use of keywords and peer evaluations, as

89 well as providing opportunities for youth to display the skills, modelling, and taking advantage

90 of teachable moments. However, coaches within this study had conflicting perspectives on

91 athletes' comprehension of and ability to transfer skills learned in the sport context to other life

92 domains. Similarly, in another study that explored explicit life skill transfer in a school-based

93 sport program, results highlighted the importance of utilizing teachable moments to promote

94 transference and draw connections to the school environment (Walsh, Ozaeta, \& Wright, 2010).

95 However, neither study fully explored the youth experience of transferring life skills as the focus

96 was predominantly on strategies coaches used for facilitating transfer.

97 Other research that has explored the concept of life skill transfer (Allen et al., 2015;

98 Hayden et al., 2015; Lee \& Martinek, 2012) from the perspective of youth participants has

99 primarily been conducted within the school context. Only one study, to our knowledge, has

100 explored life skill transfer to multiple contexts in a program that was implemented outside of the

101 school context (see Weiss, Stuntz, Bhalla, Bolter, \& Price, 2013). Most studies have focused on

102 transfer from a school-based sport context (e.g., high school sport, physical education programs,

103 afterschool programs) to a school context (e.g., Allen et al., 2015; Martinek, Schilling, \&

104 Johnson, 2001; Walsh et al., 2010). Furthermore, previous research has tended to use solely male

105 participants and analyzed data from only 1 year of program participation. Therefore this study 
106 aims to contribute to several gaps within the literature as it focused on a community-based life

107 skills program for female youth that was independent of the school environment and explored

108 explicit life skill transfer over the course of 2 years of programming. Although research has

109 started to examine if the skills developed in sport are indeed transferable to other life domains,

110 few studies have examined the practical strategies used to effectively facilitate life skill transfer

111 within youth programs.

112 It has been suggested that sport programs can foster transferable skills, yet it still remains

113 unclear how these programs should be designed to best facilitate transference (Turnnidge et al.,

114 2014). As such, the purpose of this study was twofold: (a) to examine whether participation in

115 GJWHF was able to help female youth develop and transfer life skills to various life domains

116 beyond the program and (b) to identify practical strategies perceived by youth that effectively

117 facilitated transference.

\section{Method}

119 Context

120 The Girls Just Wanna Have Fun (GJWHF) program, a physical activity-based life skills

121 program, was developed and implemented for female youth from low-income families between

122 the ages of 11 and 16 within a Boys and Girls Club (BGC) in Eastern Ontario, Canada. The

123 program was developed in partnership with a team of researchers and a local Boys and Girls

124 Club in response to an identified gender gap in BCG programming, highlighting that

125 significantly more males were participating in sport and physical activity programs than females.

126 The main objectives of GJWHF were to (a) provide physical activity opportunities, (b) facilitate

127 life skill development, and (c) enable opportunities for youth voice (for complete program

128 description; see BLIND FOR REVIEW). The GJWHF program takes on a youth-driven 
129 approach which incorporates the facilitation of meaningful youth involvement, providing youth

130 with choice and opportunities to plan (e.g., choice of physical activity type and snack,

131 opportunities to plan and lead their own life skill activity to younger youth within the club;

132 Coakley, 2011; Education Alliance, 2007).

133 The GJWHF program structure is largely based on Hellison's $(1995,2011)$ Teaching

134 Personal and Social Responsibility (TPSR) model and incorporates life skills activities from

135 Danish et al.'s (2004) Sports United to Promote Education and Recreation (SUPER) program

136 model. The TPSR model focuses on developing a strong leader-participant relationship that

137 enables gradual youth empowerment (Hellison, Martinek, Walsh, \& Holt, 2008). The GJWHF

138 program integrated the five levels of the TPSR model (personal responsibility, effort, self-

139 coaching, leadership, transference). For example, leaders encouraged youth to work towards

140 these levels (e.g., putting forth their best effort, taking responsibility for their actions), provided

141 opportunities for youth to practice these skills throughout the program, and worked to explain

142 how and why this was important (transfer). As part of the TPSR structure, a group debrief was

143 used to conclude each session whereby leaders and youth discussed successes and challenges of

144 the session. At this time, the leaders discussed with youth how and why the skills developed in

145 the program could transfer to other domains. Accordingly, the GJWHF took on an explicit

146 approach to life skills development and transfer.

147 Researchers have suggested that PYD programs should run for a period of at least 9

148 months with a minimum of 10 program sessions in order to best facilitate transference (Catalano,

149 Berglund, Ryan, Lonczak, \& Hawkins, 2004). Based on these suggestions, GJWHF ran once per

150 week for 2 years from September to May. The first year of program implementation consisted of

15130 sessions lasting $75 \mathrm{~min}$ in duration while the second year consisted of 27 sessions and 
152 increased to 90 min (based on first year recommendations; BLIND FOR REVIEW). During both

153 years, GJWHF was held at the same BGC location at no cost to participants and free

154 transportation was also provided for youth to and from the clubhouse. Five female leaders were

155 involved in each of the 2 years of programming with two leaders participating in both years of

156 program implementation.

\section{Participants}

Female youth between the ages of 11 and $16(M$ age $=12.44, S D=1.32)$ from two

159 different BGC locations met at one clubhouse per week and attended GJWHF over the course of

1602 years. Youth participants (hereafter referred to as 'youth') were from low-income families in a

161 major city in Eastern Ontario. Youth involvement in the BGC ranged from 1 month to 9 years.

162 There were 10 consistent youth (attended more than $75 \%$ of the sessions) in the first year and

163 eight consistent youth who attended the program in the second year. Some youth dropped out

164 over the course of 2 years of programming due to competing alternatives within the clubhouse.

165 All youth who participated in the program, regardless of participation rates, were invited to

166 partake in the research and were provided with parental consent and youth assent forms. A total

167 of 11 interviews (five in year 1, six in year 2) were conducted with youth who returned parental

168 consent forms over the 2 years of GJWHF (see Table 1 for complete breakdown of youth). Four

169 youth were involved in the program for both years, three of whom were interviewed at two time

170 points (at the end of the first and second years of programming). Despite the researchers' efforts,

171 scheduling conflicts arose when arranging an interview with the one remaining youth and thus

172 this youth was only interviewed at the end of the second year. Four youth participated in the

173 program for 1 year (two in year 1, two in year 2). It should be noted that participation in the 
174 research was not required for participation in the program and it was stated on the consent and 175 assent forms that participation in the research was voluntary.

\section{Procedure and Interview Guide}

Within the context of youth programs, particularly with TPSR-based programs, many

178 individuals involved are community-engaged professors acting in a dual role: program leader and

179 researcher (e.g., Hellison \& Walsh, 2002; Ward \& Parker, 2013). This study utilized this

180 approach as the first and second authors were directly involved in GJWHF as program leaders

181 and also aided in the program evaluation (e.g., conducting youth interviews). The first author

182 was involved in program development and implementation over the course of the 2 years of

183 GJWHF and the second author was involved in the second year of implementation. Interviews

184 were conducted by these authors as it has been argued that youth are more likely to open up to an

185 individual with whom they know and trust, compared to an independent interviewer (Heath,

186 Brooks, Cleaver, \& Ireland, 2009).

187 Following ethical approval from the affiliated institution's Office of Research Ethics and

188 Integrity, parental consent forms were distributed prior to the start of GJWHF and assent forms

189 were completed by all youth. A number of steps were taken in order to reduce social desirability

190 effects. First, youth were assured that their responses would remain confidential and were

191 reminded the study was voluntary in nature. Second, youth were told that the objective of the

192 study was simply to gather their perspectives of their involvement in GJWHF and that there were

193 no 'right' or 'wrong' answers. Lastly, youth were made aware that the interview was not an

194 evaluation and would not affect their involvement in the program in any way. While youth did

195 provide examples of things they did not like about the program because the purpose of this

196 manuscript was on the transference of life skills (inherently positive skills), the negative 
197 experiences were analyzed and reported elsewhere (see Bean, Forneris, \& Halsall, 2014; Bean, 198 Kendellen, Halsall, \& Forneris, 2015).

A total of 11 semi-structured interviews $(M$ age $=13.7, S D=1.1)$ were conducted with

200 eight youth over the course of 2 years of programming. Five interviews were conducted at the 201 end of the first year of program implementation and six interviews were conducted at the end of 202 the second year. During both years, youth were interviewed one week after GJWHF was over at 203 a BGC location.

204 Data were collected through semi-structured interviews, as Smith and Osborn (2008) have 205 argued they allow for flexibility, facilitation of rapport, and the ability to have in-depth 206 discussions producing rich data. The interview guide was developed based on an extensive 207 review of the PYD and programming literature (e.g., Catalano et al., 2002; Larson, 2000; Lerner 208 et al., 2005). The interview guide was modified slightly from the first to second year based on 209 the analysis of first year data, including minor adjustments and follow-up questions. The 210 interview guide aimed to explore youths' insights of how participation in GJWHF has potentially

211 impacted their life skill development and further aided in the transference of these life skills to 212 other domains (e.g., "What did you learn by being involved in the program?", "What skills have 213 you learned in the program?", "Do you plan to use the skills you've learned in the program in 214 your life?", "How do you think that skill will help you at school? At home? With friends?", 215 "What within GJWHF helped you to apply the skill to youth life?"). Probes were used to further 216 explore areas of youth experiences (e.g., "Can you give me an example of what you mean?").

217 Interviews were recorded using a digital audio-recorder and lasted from 26 to $45 \min (M=$ $21831: 33)$.

\section{Data Analysis and Results}


Interviews were transcribed verbatim by the first two authors, resulting in 161 pages of

221 transcripts (12-point font, single-spaced). Triangulation of the data was utilized, as data were

222 gathered at multiple time points providing in-depth accounts (Maxwell, 2004). An inductive

223 thematic analysis was conducted following the iterative six-step procedure specified by Braun

224 and Clarke (2006). First, the transcripts were read and reread to become familiar with the data.

225 Second, meaningful extracts of data were identified and assigned initial codes (e.g., emotional

226 regulation, respect, physical activity). Third, codes were grouped by content into overarching

227 themes (e.g., interpersonal skills). Fourth, themes were reviewed to ensure their internal

228 homogeneity (data within themes share common features) and external heterogeneity (themes are

229 distinct from one another). During this step, investigator triangulation was used (Denzin, 1984),

230 whereby a third independent researcher, a professor who helped to develop GJWHF, but was not

231 involved in program delivery or data collection and had expertise in thematic analysis, examined

232 whether the identified themes were consistent with the data collected and verified that codes and

233 themes were accurately represented. The three researchers met to discuss any coding

234 discrepancies. Minor discrepancies occurred (e.g., labelling of themes, placement of quotes

235 under themes) which were discussed among the researchers until agreement was reached. These

236 changes occurred in the fifth step, when themes were refined by assigning specific names to the

237 themes, with particular emphasis placed on ensuring that each theme was consistent with the

238 findings within the overall data set. The sixth step involved writing the manuscript, whereby

239 researchers selected the quotes that they believe best reflected the participants' lived experiences,

240 in line with the purpose of the study.

241 The results are organized in three main sections according to life skills youth believed

242 they transferred from participating in GJWHF including (a) intrapersonal skills, (b) interpersonal 
243 skills, and (c) physical activity. Within each section, subthemes are outlined as well as the

244 strategies used by program leaders to explicitly teach the development and transfer of life skills

245 are described, where appropriate. Pseudonyms were created to protect participants' rights to

246 anonymity. Table 2 outlines activities utilized within GJWHF, youth perceptions of life skills

247 learned, and contexts in which the life skills were transferred.

248 Intrapersonal skills. The youth spoke of how participation in GWHF helped facilitate

249 the development and transference of several intrapersonal skills, such as emotional regulation,

250 focus, and goal setting. For the purposes of this study, emotional regulation is defined as

251 exercising control over one's emotions; focus is directing one's attention and effort towards a

252 specific task; and goal setting is the process of deciding what one wants, planning how to get it, 253 and working towards it.

254 Emotional regulation. Many youth discussed how during their involvement in GJWHF 255 they believed they developed skills to manage their emotions, which could be applied in other 256 areas of their lives. Emily, who was involved in the first year of GJWHF, highlighted that during 257 her involvement in the program she believed she learned the value of being able to control her 258 emotions: "The leaders taught you how to relax ...like when you're mad, how to control yourself

259 and I think that it's very important because when I got mad at some people it [emotional

260 regulation skills] helped me." Emily commented on how she believed the emotional regulation

261 skills learned in GJWHF have transferred and helped her manage her frustrations at school: "I

262 use it [emotional regulation skills] now because at school I got really mad and I just breathed

263 three times and I went to the washroom for two minutes and then I came back and everything

264 was fine." Other youth mentioned how GJWHF taught them that physical activity itself could be

265 used as an activity to help manage stress. For example, Amina, who participated in the second 
year of GJWHF, believed she has been able to use the emotional regulation skills learned in the program to manage stressful situations at home, specifically by using dance:

Amina also believed the emotional regulation skills transferred to school: explicitly facilitate the development and transfer of emotional regulation. First, youth spoke of

278 how the leaders taught deep breathing techniques to encourage youth to take deep breaths when 279 feeling upset and/or frustrated. Second, the leaders encouraged youth to think about one's body 280 as a bowl of cooked spaghetti to try and relax. Laura, who participated in both years of GJWHF, 281 described how she applied these breathing and relaxation techniques in her daily life: Relaxation was a key one that we learned in the program. When we did breathing tighten your body and then relax it out - it taught me how to relax more. If you're in a

287 day and I actually used it [breathing exercise] and it actually worked! I got calmer and I was 288 good with the test and I was like 'whoa it works!'” Additionally, Julie, who was involved in 
289 GJWHF for both years, discussed one activity in which youth made Power Bracelets where they

290 picked one positive word (e.g., relax, confidence, focus) that they could identify with and made a

291 bracelet with this word on it. Although the primary goal of this activity fell within the skills of

292 self-talk and thought control, the words youth picked for themselves had various meanings and

293 helped with several life skills that had been incorporated within the program. Julie mentioned

294 how the bracelet reminded her to use breathing exercises when she felt frustrated at school:

295 "Whenever my teacher would get me mad, I would just sigh, then I know she can't get to me

296 because I'm looking at my bracelet and I'm calming down. I use my breathing too."

297 Focus. Additionally, youth discussed how GJWHF helped them to develop focus. For

298 example, Laura mentioned how she believed her involvement in GJWHF helped her learn how to

299 focus on the specific task at hand which she has transferred and helped her complete her

300 homework: It [GJWHF] taught me to focus on one thing at a time and then go to another. I have six different classes so I have different assignments and I used to focus on two different assignments, but now [after GJWHF] I think it's better to focus on just one, get that done

305 To explicitly teach focus, youth completed the Focus Grid activity, where they were provided 306 with a paper containing a grid of numbers in which they had to focus and locate various numbers 307 in the grid within a certain amount of time. After doing the activity a few times, the leaders 308 distracted the youth by making noises (e.g., banging on tables, yelling, humming) to encourage 309 youth to try focus and in order to find the numbers on the grid despite distractions. Kayla, who 310 was involved in GJWHF for both years, highlighted what she learned from this activity: 
At one point it was quiet and then at another point there was banging on the tables which made it more difficult. When it's too loud it's harder to focus and if I'm loud during a it or not and some people have to improve on that, like I have improved on that.

316 Kayla went on to discuss how she applied what she learned from this activity to other contexts in 317 her life: "I have used it [focus] a couple times, but I know I should use it more because 318 sometimes I am a disruption at school, not meaningfully though.”

319 Goal setting. To facilitate goal setting, the leaders organized an activity referred to as

320 Dare to Dream in which youth had to write down one of their dreams and describe the goals they

321 needed to set in order to achieve this particular dream. Sara, who participated in both years of 322 GJWHF, described how her dream was to be a chef and that to be successful she learned the 323 importance of practicing her cooking skills on a regular basis: "When I grow up I want be a chef. 324 I want be like Gordon Ramsay [famous chef]. I want to have my own cooking shows, so to do 325 that I cook every night. I keep that goal alive.” Similarly, Sara specified how learning to set goals 326 in GJWHF was a lesson that transferred and helped her set goals at school: "I set a goal to do 327 better in academics...last time I got an $82 \%$ in visual arts but now I'm working towards $90 \%$."

328 When asked if the program made Julie think differently about herself or her future, she outlined 329 the importance of setting goals:

330 Yes, the leaders taught me how to make goals and then I follow those goals to my 331 future...so when we did our goals...we did it at least twice or three times in the program 332 so then you get more used to it, so then the goal is finally reached...constantly working 
towards it. One goal I remember specifically because I'm still working on it is to get in an elevator without freaking out because I hate elevators.

335 Lastly, Kayla identified that the use of debriefs at the end of each session helped her to facilitate

336 the transfer of intrapersonal skills: "We would reflect on how self-control and confidence-you

337 know, at the end - we would reflect on how we participated in the program that day, what we

338 learned, and how we could use it."

Interpersonal skills. Interpersonal skills, including respect, responsibility, and social

340 skills were identified by youth as skills learned within the program and transferred to various life

341 domains. For the purposes of this study, respect is defined as showing consideration, courtesy,

342 and care for someone or something; responsibility is being accountable and being answerable to

343 one's actions; and the development of social skills refers to the ability to interact and

344 communicate with others.

345 Respect. According to the interviews, youth indicated how respect was an important skill 346 they learned during their participation in GJWHF and subsequently transferred and applied in 347 other domains. Most youth felt that they learned how to act in a respectful manner by showing 348 consideration for others' feelings. Kristen, who was involved in the first year of GJWHF, felt 349 that the program taught her how to respect others by appreciating diversity. Specifically, Kristen 350 spoke of one specific activity where a photographer came into GJWHF to take the girls' pictures 351 to be used in a scrapbook with the goal of increasing confidence and empowering the girls:

352 I learned a lot about accepting differences; that not everyone functions or acts the same 353 way...so it's helped me accept that everyone has their own differences, their own 354 qualities and strengths. When we were taking the pictures, it made me realize this 355 because I was looking at everybody's pose and was like 'wow everybody's pose is 
Kristen further elaborated on how she believed she has internalized the life skill of respect,

which has transferred and helped her demonstrate respect for her peers at school: different; they're not like mine they're not going to have the same smile as me or the same eyes.' It sort of made me realize that if everybody's poses are different that means they're different so why not accept it.

You have people who are so alone and teased every day because they look or act different. It's made me realize 'what has she done wrong?' I used to be part of that, but then [after GJWHF] I was like 'what was the point of doing that it's really not worth it.'

Emily specified how the program leaders modelled respectful behavior which helped her internalize this skill and apply it other areas of her life:

I now respect others by listening better, if they're [friends, teachers] talking to me, I will listen and not talk to somebody else. In the program, the leaders respected you when you were talking and they asked others not to speak because they want to show you respect. I think that helps me because if they show respect, I should show respect to others too. Emily further emphasized how the program helped her to understand respect, specifically as it relates to being grateful when others do nice things for her: When the girls group [GJWHF] gave us things, like snacks and lip gloss, you appreciate and respect it and you don't just throw it away, you say 'thank you'. So at school and at my house and with my friends, when people give me something or do something nice for me, I wouldn't just disown it or wouldn't care, I'd be thankful and respect them for it. Sara described how during the Rose and Thorn activity, a relational activity done at the beginning of each program session in which youth share one rose (something good that happened 
that week) and one thorn (something not so good that happened that week), helped her learn how

379

380

to respect her peers:

When we were in the circle and did something we weren't supposed to, we had to come forward and say what we did; you had to own up to what you did. When we were having the group discussions you had to be respectful to whoever's talking, not interrupt them.

Sara went on to discuss how she applied the respectful behaviors learned at GJWHF when playing basketball: "When we play basketball, we can't be rude to the refs or other players. If we see something, say double dribble, you can't just stop the game—I'm not the ref, I'm a playerso you just let that person do their job."

Responsibility. Moreover, Sara indicated how she applied respect and responsibility in her daily life: "I use this at home because when my mom needs help, I would respect her and step up and help her with the dishes." Additionally, Kayla discussed how taking more responsibility has helped her in three contexts of her life: Responsibility has helped me at school because it has pushed me to do my homework because that's my responsibility. At home, to not forget my homework and to do it and get my tests signed. And it has helped me with my friends more because before I would get detention at lunch and my friends have gone to recess. So now I'm not sitting in class getting in trouble anymore, I can actually spend time with them.

Kristen discussed how she developed a sense of responsibility regarding how to act in public: The program has [helped me] when it comes to teamwork and we have group activities or even if we're going out in public, there's a sense of responsibility there that we have to take and then actions we have to do. There are certain ways you can act and certain ways you can't act. There are certain ways to speak and certain ways not to speak. 
401 Lastly, when asked how the program has helped her transfer the skill of responsibility to other

402 life contexts, Julie discussed the importance of debriefing: "Just taking the time in the program to

403 reflect on different characteristics about yourself made me think about it a little bit more, you

404 know, in my life."

Social skills. The findings also illustrate how the opportunities to socialize and work

406 cooperatively with other youth in GJWHF helped the youth develop social skills. Laura

407 explained how the activity Knights, Horses, and Cavaliers, a cooperative game done in pairs,

408 helped her to be more inclusive and work as a team: "Teamwork helped me with my friends, to

409 not leave people out in sports. With family too, when you go outside, you ask your brother if he

410 wants to go, you don't just leave and not ask, you include others." Moreover, some youth talked

411 about how GJWHF provided them with opportunities to meet and socialize with other youth. For

412 example, Laura mentioned how the leaders divided the group into smaller groups which forced

413 her to socialize with new people: “It [GJWHF] helped me because I wasn't always with my

414 friends, I was with other people because the leaders separated us [into groups] so I talked with

415 other people." Furthermore, Sara also recognized this change in Laura over the course of

416 GJWHF and noted:

417 [Laura], she improved. Like before she's 'oh, I don't like this person because of their 418 appearance', but now she actually understands that you can't judge someone on how they

419 look. She now judges them on personality and knows to be nice and approach them.

420 Julie talked about how the program helped her gain confidence pertaining to her social skills

421 which has helped her act in a confident manner in her everyday life:

422 I used to shy away from participating and now, after the program, I'm not that shy

423 anymore. I'm not afraid to speak out anymore. It [GJWHF] helped me, like I think all the 

stuff we went through, the focus and empowerment activities...it helped me to overcome my fear and now I'm not so shy.

426 When participating in the Power Bracelets activity previously described, Emily mentioned how 427 she wrote the word 'brave' on her bracelet to encourage her to try new things which was a lesson 428 that transferred and helped her take initiative to communicate her ideas at school: We made the bracelets and wrote a word on it, I put 'brave'...In class I wouldn't usually answer any questions, but now if I know the question I will just put my hand up and I will

434 Lastly, Sara discussed how she gained confidence in her social skills from participating in 435 GJWHF: "I never thought I would have the courage to actually go up to a person and introduce 436 myself, but with GJWHF I wasn't forced, I was encouraged and acknowledged to lead and 437 interact with people, which made it easier." Sara further highlighted how she has used this skill 438 to meet new people while camping: "There is a girl at my campsite, she was new to the site, so I 439 just saw her trailer pull up and then just asked her if she wanted to go to the park." Physical activity. Many youth spoke of how they learned to enjoy being physically

441 activity during GJWHF which was a skill that transferred and helped them engage in physical 442 activity outside of the program. Laura mentioned how playing basketball for the first time in 443 GJWHF was a fun experience that shaped her decision to play basketball in her community: 444 Before GJWHF I didn't really play basketball and then we played basketball at the 445 program and it was fun and now I started doing it here [BGC]. In the summer time I'm 
doing it at [name of basketball league] because they have a team and at the BGC in the summertime we're having a team too. So now I'm going to be a part of both of them.

Likewise, Bailey, who participated in the second year of GJWHF, described how she enjoyed

449 playing a wide range of sports in GJWHF because it provided her with opportunities to socialize

450 and work collaboratively with other youth. She discussed how playing sports was a positive

451 experience that transferred and encouraged her to join sport teams in her community: GJWHF made me feel pumped up about joining sports teams and it helped because I want to join more sports team when I'm older like hockey, soccer, basketball because working together with other people is actually fun and you get to know them and can become really great friends. The program made me think about maybe starting to do more sports — actually I have started another program, a [community] hockey program.

457 Finally, Julie spoke of how she developed an interest for physical activity during her

458 participation in GJWHF which was an important lesson that transferred and helped her to be 459 physically active during afterschool hours: "Usually when I go home I'd just sit down and play

460 on my phone, but now [after GJWHF] I like to go outside and play and interact with my

461 neighbors or my sister." Julie later provided a tangible example of how she believed the physical 462 competencies she developed through her involvement in GJWHF transferred and helped her run

463 further distances in physical education classes. She described how she felt proud of this

464 accomplishment: "At school we have a track and since the program, I can run a lap and a half 465 without stopping. It makes me feel good...I improved on that because before I wouldn't even be 466 able to run one lap." 
The purpose of this study was twofold: (a) to examine whether the GJWHF program was

469 able to help female youth develop and transfer life skills to various life domains beyond the

470 program and (b) to identify practical strategies perceived by youth that effectively facilitated

471 transference. Findings from this study indicated that youth believed they were able to develop

472 and transfer life skills from participating in the program. More specifically, the youth believed

473 they were able to transfer intrapersonal skills (e.g., emotional regulation, focus, and goal setting),

474 interpersonal skills (e.g., respect, responsibility, and social skills), and physical activity skills to

475 contexts beyond GJWHF which included school, home, peer group, and other sport

476 environments. A unique aspect of this study is that findings extend an understanding of how

477 community-based youth programming contexts can facilitate life skill transfer, as research has

478 predominantly been conducted within the context of school. Findings from this study indicated

479 numerous contexts in which youth believed they were able to transfer life skills to outside of

480 GJWHF which may speak to the benefit as using a community-based context instead of a school-

481 based context where transference may be more limited to the school environment.

482 Moreover, as GJWHF ran for 2 consecutive years, analyzing data from both years of

483 programming allowed for a better understanding of the practical strategies that youth believed

484 were effective in helping them learn transferable skills. The findings of the current study support

485 previous research that has emphasized the importance of intentionally teaching life skills to

486 foster greater likelihood that youth are able to transfer skills (Danish et al., 2004; Gould \&

487 Carson, 2008; Martinek et al., 2001). This study is in line with past research in which

488 deliberately facilitating transfer within youth programs has led to positive outcomes for youth

489 (Hayden et al., 2015; Hellison \& Walsh, 2002; Walsh et al., 2010). Moreover, results support 
490 previous findings from Weiss et al. (2013) as youth within The First Tee were able to transfer

491 skills learned in golf to contexts, such as school, home, with friends, and in the workplace.

492 One of the novel contributions of this study was documenting the specific activities youth

493 believed to be useful in GJWHF to facilitate life skill transfer which can be utilized by other

494 programmers. One of the main strategies used to intentionally teach life skills within the program

495 context was the activities used to introduce and provide opportunities to practice the skills. For

496 youth to gain the confidence and awareness necessary to successfully transfer skills, researchers

497 have argued that a deliberate approach should be taken by providing concrete examples

498 throughout the program session of how the life skills can be applied beyond the program (Danish

499 et al., 2004; Gould \& Carson, 2008). In the current study, youth discussed specific activities in

500 which they believed were crucial in the facilitation of intrapersonal and interpersonal skills in

501 other contexts, such as learning breathing techniques pertinent in emotional regulation, making

502 Power Bracelets as a reminder for self-talk and emotional regulation, and participating in the

503 Dare to Dream activity to practice setting goals. These activities were integrated into

504 programming specifically to take on an explicit approach to life skill development. Furthermore,

505 throughout these activities, leaders provided examples and created tangible links between the

506 activities and external life contexts, with the goal of increasing youths' awareness of contexts in

507 which such skills can be applied. As previous studies have recognized the importance of utilizing

508 teachable moments (Camiré et al., 2012; Walsh et al., 2010), the current study reinforces the

509 importance of not only taking opportunities that arise, but also ensuring leaders facilitate such

510 opportunities regularly to reinforce skills.

511 In line with this, an effective strategy found within this study was the importance of

512 conducting a debrief at the end of a program session. Specifically, the debriefs (ranging from 5 to 
$51310 \mathrm{~min}$ ) were held as a group at the end of the program session and were used to summarize the

514 life skills and facilitate informal discussions moderated by the leader on how these skills could

515 be applied to other life domains (e.g., What skill(s) did you learn today; Where could you apply

516 these skills in your life? How?). This finding is consistent with past research by Walsh et al.

517 (2010) which outlined the importance of integrating discussions throughout the program related

518 to skill transfer to other life contexts. Engaging youth in these debriefs and the process of

519 reflection has been shown to increase the likelihood of successful transfer (Allen et al., 2015;

520 Gould \& Carson, 2008; Weiss et al., 2013). Therefore, having youth be actively engaged in the

521 debrief may help them personally relate to their life experiences and contexts, while leaders play

522 an active and supportive role in this process. Similarly, findings from Allen et al. (2015)

523 indicated the use of focus groups, as part of the reflection process, enabled youth to share

524 knowledge with their peers, which youth believed to be more beneficial than simply having the

525 leaders' communicate the same information. As such, results from this study may provide initial

526 evidence of the value of incorporating an explicit approach, such as a structured debrief, that

527 addressed various contexts in which life skills can be transferred. Therefore, incorporating an

528 interactive debrief would be a useful practical recommendation for future programmers,

529 including GJWHF leaders.

$530 \quad$ Findings from this study reinforce the importance of utilizing a sport and/or physical

531 activity context for female youth programming as youth in GJWHF were previously identified as

532 not engaging in physical activity programming within the BGC. This finding may speak to the

533 unique sample utilized within this study, while most studies exploring life skill transfer in youth

534 programming have targeted solely male or mixed-genders participants, this is one of the first

535 studies to explore solely female youth perspectives. Therefore, utilizing this environment helped 
536 female youth develop physical activity competence as it was acknowledged that participation in

537 GJWHF was a catalyst for further sport and physical activity participation. As such, facilitating

538 opportunities for the development of physical activity competence helps in the facilitation of

539 physical activity participation in adulthood (Telama et al., 2005), particularly in female youth

540 from families living on low-incomes as this group has the lowest rates of physical activity (Gray

541 et al., 2014). Moreover, the transfer of social skills may be particularly relevant for youth in this

542 study, as female youth has been known to value relationships and social connections (Coleman,

543 Cox, \& Roker, 2008; Jordan, 2013; Meyers, 2003) and the environment fostered within GJWHF

544 may have been effective in developing such skills (BLIND FOR REVIEW).

545 The delivery of a well-structured program is crucial for youth engagement and

546 development. Specifically, the utilization of a youth-driven approach, including providing

547 opportunities for leadership, was acknowledged by youth as important in the development and

548 transference of social skills. Using the TPSR model as one of the primary frameworks in

549 GJWHF helped facilitate this, as a key value in this model is providing the youth with gradual

550 empowerment throughout the program, which includes leadership opportunities (Hellison et al.,

551 2008). Previous studies conducted with GJWHF have identified this as an imperative component

552 to program success (BLIND FOR REVIEW), yet this is one of the first empirical studies to

553 outline how particular strategies within a youth-driven program can not only foster life skill

554 development, but also transference. Turnnidge et al. (2014) acknowledge having a solely adult-

555 driven approach may not be the best approach, and as such, GJWHF utilized a combination of

556 youth- and adult-driven approaches; however, future research should aim to further explore what

557 the optimal balance is between these two approaches. Additionally, having clear rules and

558 expectations outlined for the group was important, as youth discussed the importance of 
understanding how to behave as part of the GJWHF group in public was critical in transferring

560 the life skill of respect. In line with this, youth discussed the importance of the program leaders

561 modelling respectful behavior which impacted the youth and their influence on transference.

562 This reinforces the importance of external assets (Weiss et al., 2013; Petitpas et al., 2005).

563 Lastly, although not identified as a specific strategy for facilitating transfer, the length of

564 program itself may have helped influence skill transference. As mentioned, Catalano et al. (2004)

565 suggest that youth development programs should be implemented for a minimum of 10 sessions

566 over the course of 9 months to aid in life skills transference. The current study examined a

567 program that ran for 9 months over the course of 2 years, with a total of 57 implemented

568 program sessions, which could help to explain youth's positive experiences with life skills

569 transference within this program. Similar findings have been found by Walsh et al. (2010) who

570 evaluated a 2-year, 45 session TPSR-based program in which many participants outlined the

571 ability to transfer skills learned within the program to external contexts.

\section{Limitations and Future Directions}

573 This study was successful in understanding if and what strategies were used within

574 GJWHF to develop and facilitate life skill transfer for youth over 2 years of programming, yet

575 there were limitations. First, as is often the case in program evaluations, there is potential for

576 social desirability as program leaders conducted youth interviews which had the potential for

577 influence. To minimize this several steps outlined above were taken to minimize social

578 desirability when conducting the interviews. However, as earlier mentioned, youth are often

579 more likely to open up to an individual they know, rather than an independent interviewer (Heath

580 et al., 2009). Second, the data were based on participant self-report through the use of interviews

581 and therefore results were based on perceptions as opposed to observational data. Third, although 
582 the data collected were from youth who consistently participated in the program, in some cases

583 for 2 years, the data are based on one particular program with a relatively small sample size.

584 Therefore, the generalizability of the results are limited. Based on the findings of this study, there

585 are also a number of future directions for research on transfer such as further understanding the

586 transference of skills to multiple life contexts, barriers to life skill transfer, and how leaders can

587 balance using an explicit approach to teach transfer while still incorporating a youth-driven 588 approach.

589 In conclusion, this is the first known study to look at all female youth and one of few

590 studies that examined transfer beyond the context of school and to multiple contexts.

591 Furthermore, it has been argued that the TPSR model is an exemplary youth development model;

592 however few studies have provided sufficient empirical findings of transference efficacy beyond

593 the scope of the delivered program (Walsh et al., 2010). This study provides evidence for this

594 identified gap. The applied nature of this study highlights practical strategies for programmers on

595 how to facilitate life skill transfer within a youth program. It is critical to have training to teach

596 program leaders how to intentionally integrate life skills within such programs, teaching not only

597 the importance of facilitating transfer throughout program sessions, but also outlining how to

598 facilitate this process by using strategies outlined in this study (e.g., intentional life skills

599 activities, interactive debrief). Moving forward, it is our hope that researchers and practitioners

600 can take these strategies and integrate them into programming to help youth learn life skills and

601 apply these skills in multiple life domains in which they engage. 
References

604 Allen, G., Rhind, D., \& Koshy, V. (2015). Enablers and barriers for male students transferring life skills from the sports hall into the classroom. Qualitative Research in Sport, Exercise and Health, 7, 53-67. doi:10.1080/2159676X.2014.893898

607 Braun, V., \& Clarke, V. (2006). Using thematic analysis in psychology. Qualitative Research in Psychology, 3, 77-101. doi:10.1191/1478088706qp063oa

609 Camiré, M., \& Trudel, P. (2010). High school athletes’ perspectives on character development 610 through sport participation. Physical Education and Sport Pedagogy, 15(2), 193-207. doi:10.1080/17408980902877617

612 Camiré, M., Trudel, P., \& Forneris, T. (2012). Coaching and transferring life skills: Philosophies 613 and strategies used by model high school coaches. The Sport Psychologist, 26, 243-260.

614 Catalano, R., Berglund, M., Ryan, J., Lonczak, H., \& Hawkins, J. (2004). Positive youth development in the United States: Research findings on evaluations of positive youth development programs. The Annals of the American Academy of Political and Social Science, 591, 98-124. doi:10.1177/0002716203260102

Coakley, J. (2011). Youth sports: What counts as “positive development?” Journal of Sport \&

620 Coleman, L., Cox, L., \& Roker, D. (2008). Girls and young women's participation in physical activity: Psychological and social influences. Health Education Research, 23, 633-647.

622 Damon, W. (2004). What is positive youth development? The ANNALS of the American 
624 Danish, S. J., Forneris, T., Hodge, K., \& Heke, I. (2004). Enhancing youth development through sport. World Leisure Journal, 46(3), 38-49. doi 10.1080/04419057.2004.9674365

Danish, S. J., \& Nellen, V. C. (1997). New roles for sport psychologists: Teaching life skills through sport to at-risk youth. Quest, 49, 100-113.

Denzin, N. (1984). The research act. Englewood Cliffs, NJ: Prentice Hall.

629 Education Alliance. (2007). Positive youth development: Policy implications and best practices.

630 Charleston, WV: The Education Alliance.

631 Gould, D., \& Carson, S. (2008). Life skills development through sport: Current status and future directions. International Review of Sport and Exercise Psychology, 1, 58-78.

634 Gray, C. E., Larouche, R., Barnes, J. D., Colley, R. C., Bonne, J. C., Arthur, M., . . Janssen, I. (2014). Are we driving our kids to unhealthy habits? Results of the Active Healthy Kids Canada 2013 report card on physical activity for children and youth. International Journal of Environmental Research and Public Health, 11, 6009-6020. doi:10.3390/ijerph110606009

Hayden, L. A., Whitley, M. A., Cook, A. L., Dumais, A., Silva, M., \& Scherer, A. (2015). An exploration of life skill development through sport in three international high schools.

643 Heath, S., Brooks, R., Cleaver, E., \& Ireland, E. (2009). Researching young people's lives. 
645 Hellison, D., Martinek, T., Walsh, D., \& Holt, N. (2008). Sport and responsible leadership among youth. In N. Holt (Ed.), Positive youth development through sport (pp. 49-60). New York: Routledge.

Hellison, D., \& Walsh, D. (2002). Responsibility-based youth programs evaluation: Investigating the investigations. Quest, 54, 292-307. doi:10.1080/00336297.2002.10491780

Hellison, D. (1995). Teaching responsibility through physical activity. Champaign, IL: Human Kinetics.

652 Hellison, D. (2011). Teaching responsibility through physical activity $\left(3^{\text {rd }}\right.$ ed). Champaign, IL: Human Kinetics.

654 Holt, N. L., Tink, . N., Mandigo, J. L., \& Fox, K. R. (2008). Do youth learn life skills through 655 their involvement in high school sport? A case study. Canadian Journal of Education, 31(2), 281-304. doi:10.2307/2046670

657 Jordan, J. V. (2013). Relational resilience in girls. In S. Goldstein \& R. B. Brooks (Eds.), Handbook of resilience in children ( $2^{\text {nd }}$ ed, pp. 73-86). New York: Springer.

Lerner, R. M. (2012). Developmental science: Past, present, and future. International Journal of Developmental Science, 6, 29-36. Doi:10.3233/DEV-2012-12102

Martinek, T., Schilling, T., \& Johnson, D. (2001). Transferring personal and social responsibility

Maxwell, J. A. (2004). Causal explanation, qualitative research, and scientific inquiry in of underserved youth to the classroom. The Urban Review, 33, 29-45. education. Educational Researcher, 33, 3-11. doi:10.3102/0013189X033002003 Schwarz (Eds.), Well-being: Foundations of hedonic psychology (pp. 374-391). New York: Russell Sage Foundation. 
668 669

670

671

672

673

674

675

676

677

678

679

680

681

682

683

684

685

686

687

688

Orlick, T. (2011). Positive living skills: Joy and focus for everyone. Toronto, Ontario: General Store Publishing House.

Papacharisis, V., Goudas, M., Danish, S. J., \& Theodorakis, Y. (2005). The effectiveness of teaching a life skills program in a sport context. Journal of Applied Sport Psychology, 17(3), 247-254. doi:10.1080/10413200591010139

Petitpas, A. J., Cornelius, A. E., Van Raalte, J. L., \& Jones, T. (2005). A framework for planning youth sport programs that foster psychosocial development. The Sport Psychologist, 19, 6-80.

Smith, J. A., \& Osborn, M. I. (2008). Interpretative phenomenological analysis. In J. A. Smith (Ed.), Qualitative psychology: A practical guide to methods (2nd ed.). London: Sage Publications.

Snyder, C. R., \& Lopez, S. J. (2002). Handbook of positive psychology. Oxford, United Kingdom: Oxford University Press.

Telama, R., Yang, X., Viikari, J., Välimäki, I., Wanne, O., \& Raitakari, O. (2005). Physical activity from childhood to adulthood: A 21-year tracking study. American Journal of Preventive Medicine, 28, 267-273. doi:10.1016/j.amepre.2004.12.003

Turnnidge, J., Côté, J., \& Hancock, D. J. (2014). Positive youth development from sport to life: Explicit or implicit transfer? Quest, 66, 203-217. doi:10.1080/00336297.2013.867275

Walsh, D. S., Ozaeta, J., \& Wright, P. M. (2010). Transference of responsibility model goals to the school environment: Exploring the impact of a coaching club program. Physical Education \& Sport Pedagogy, 15, 15-28. doi:10.1080/17408980802401252 
689 Ward, S., \& Parker, M. (2013). The voice of youth: atmosphere in positive youth development 690 program. Physical Education and Sport Pedagogy, 18, 534-548.

691 doi:10.1080/17408989.2012.726974

692 Weiss, M. R., Stuntz, C. P., Bhalla, J. A., Bolter, N. D., \& Price, M. S. (2013). 'More than a 693 game': Impact of The First Tee life skills programme on positive youth development: 694 project introduction and Year 1 findings. Qualitative Research in Sport, Exercise and 695 Health, 5, 214-244. doi:10.1080/2159676X.2012.712997

696 
Table 1

699

Demographic Information of Participants

\begin{tabular}{lccc}
\hline Pseudonym & Age & $\begin{array}{c}\text { Involvement } \\
\text { (year 1, year 2, both) }\end{array}$ & Number of interviews \\
\hline Emily & 11 & 1 & 1 \\
Kristen & 13 & 1 & 1 \\
Amina & 12 & 2 & 1 \\
Bailey & 11 & 2 & 1 \\
Sara & 14 & Both & 2 \\
Julie & 13 & Both & 2 \\
Kayla & 13 & Both & 2 \\
Laura & 14 & Both & \\
\hline
\end{tabular}

700

701 
Table 2

704 Examples of activities utilized within GJWHF with youth perceptions of life skills learned 705 and contexts, outside of the program, to which youth identified as successfully transferring 706 the life skills.

\begin{tabular}{|c|c|c|c|}
\hline $\begin{array}{l}\text { Activities } \\
\text { utilized within }\end{array}$ & Activity description & Life skills learned & $\begin{array}{l}\text { Contexts of } \\
\text { life skill }\end{array}$ \\
\hline GJWHF & & & transfer \\
\hline Rose and thorn & $\begin{array}{l}\text { Group activity in which youth share } \\
\text { one positive and one challenging } \\
\text { experience that occurred that week }\end{array}$ & Respect & Sport \\
\hline Deep breathing & $\begin{array}{l}\text { Youth learn how to take deep breaths } \\
\text { to relax }\end{array}$ & $\begin{array}{l}\text { Emotional } \\
\text { regulation }\end{array}$ & School \\
\hline Spaghetti & Youth imagine themselves feeling like & Emotional & School; Home \\
\hline exercise $^{a}$ & spaghetti & regulation & \\
\hline Power bracelets ${ }^{\mathrm{b}}$ & $\begin{array}{l}\text { Youth design a bracelet with a word } \\
\text { they believe will be most helpful to } \\
\text { them in tough situations }\end{array}$ & $\begin{array}{l}\text { Positive self-talk; } \\
\text { Emotional } \\
\text { regulation }\end{array}$ & School \\
\hline Focus grid $^{c}$ & $\begin{array}{l}\text { Youth focus and locate various } \\
\text { numbers on a paper containing a grid } \\
\text { of numbers within a certain amount of }\end{array}$ & Focus & School \\
\hline
\end{tabular}


time

Dare to dream $\quad$ Youth write down their dreams and $\quad$ Goal Setting; $\quad$ School

discuss them with other youth

Positive future

orientation

$\begin{array}{llll}\text { Knights, horses, } & \text { A cooperative game that emphasizes } & \text { Social Skills - } & \text { Home; Peer } \\ \text { cavaliers } & \text { teamwork, social support, and } & \text { Teamwork; } & \text { group; Sport } \\ & \text { communication } & \text { Inclusion } & \\ \text { Photographs } & \text { Youth had opportunity to have } & \text { Respect; } & \text { School; Peer } \\ & \text { portfolio pictures taken by a } & \text { Appreciating } & \text { Group } \\ & \text { photographer } & \text { differences; } & \\ & & \text { Confidence } & \\ \text { Integrating } & \text { Sport/Physical activity component was } & \text { Physical activity } & \text { Sport/Physical } \\ \text { physical activity } & \text { integrated into every session. Youth } & \text { competence; } & \text { activity; } \\ \text { in each session } & \text { were provided with the choice as to } & \text { Perseverance; } & \text { School; Home } \\ & \text { what activity they wanted to engage in } & \text { Emotional } & \end{array}$

Note: Activity descriptions can be found from the following sources: ${ }^{a}$ Spaghetti exercise -

708 Orlick, 2011 (see reference list); ${ }^{\text {b }}$ Power bracelets - http://almastoller.blogspot.ca/2011/01/how-

709 to-make-paper-bracelet.html; ${ }^{\mathrm{c}}$ Focus grid — http://coachspilker.blogspot.ca/2011/04/can-you-

710 focus-and-concentrate.html; ${ }^{\mathrm{d}}$ Knights, horses, cavaliers -

711 http://www.ultimatecampresource.com/site/camp-activity/knight-horse-cavalier.html 
